\title{
Update: Interim Guidelines for Health Care Providers Caring for Infants and Children with Possible Zika Virus Infection — United States, February 2016
}

\author{
Katherine E. Fleming-Dutra, MD¹; Jennifer M. Nelson, MD²,3; Marc Fischer, MD4; J. Erin Staples, MD, PhD ${ }^{4}$; Mateusz P. Karwowski, MD 2,5 ; \\ Paul Mead, MD ${ }^{4}$ J Julie Villanueva, $\mathrm{PhD}^{6}$; Christina M. Renquist, $\mathrm{MPH}^{7}$; Anna A. Minta, MD²,8; Denise J. Jamieson, MD ${ }^{7}$; Margaret A. Honein, PhD 7 ; \\ Cynthia A. Moore, $\mathrm{MD}, \mathrm{PhD}^{7}$; Sonja A. Rasmussen, $\mathrm{MD}^{10}$
}

On February 19, 2016, this report was posted as an MMWR Early Release on the MMWR website (http://www.cdc.gov/mmwr). CDC has updated its interim guidelines for U.S. health care providers caring for infants born to mothers who traveled to or resided in areas with Zika virus transmission during pregnancy and expanded guidelines to include infants and children with possible acute Zika virus disease (1). This update contains a new recommendation for routine care for infants born to mothers who traveled to or resided in areas with Zika virus transmission during pregnancy but did not receive Zika virus testing, when the infant has a normal head circumference, normal prenatal and postnatal ultrasounds (if performed), and normal physical examination. Acute Zika virus disease should be suspected in an infant or child aged $<18$ years who 1 ) traveled to or resided in an affected area within the past 2 weeks and 2) has $\geq 2$ of the following manifestations: fever, rash, conjunctivitis, or arthralgia. Because maternal-infant transmission of Zika virus during delivery is possible, acute Zika virus disease should also be suspected in an infant during the first 2 weeks of life 1) whose mother traveled to or resided in an affected area within 2 weeks of delivery and 2) who has $\geq 2$ of the following manifestations: fever, rash, conjunctivitis, or arthralgia. Evidence suggests that Zika virus illness in children is usually mild (2). As an arboviral disease, Zika virus disease is nationally notifiable. Health care providers should report suspected cases of Zika virus disease to their local, state, or territorial health departments to arrange testing and so that action can be taken to reduce the risk for local Zika virus transmission. As new information becomes available, these guidelines will be updated: http://www.cdc.gov/zika/.

Zika virus is primarily transmitted to humans through the bite of Aedes species mosquitoes, most commonly Aedes aegypti and possibly Aedes albopictus (3). Zika virus was first detected in the Region of the Americas (Americas) in Brazil in the spring of 2015 (4) and had spread to 26 countries and territories in the Americas as of February 17, 2016 (http://www.cdc.gov/zika/geo/ active-countries.html). In October 2015, a marked increase in the number of infants with microcephaly was reported in Brazil (5). Because of the temporal and geographic occurrence of Zika virus infection in pregnant women before the reported increase in microcephaly, a possible association with prenatal Zika virus infection was postulated (5). Laboratory evidence from a limited number of cases with microcephaly has supported this potential association $(6,7)$. Other documented modes of Zika virus transmission include intrapartum transmission from a mother with viremia to her infant, sexual transmission, and laboratory exposures (8-11). Additionally, blood transfusion (10) and organ or tissue transplantation pose theoretical risks for transmission. There is no reported evidence of transmission through breastfeeding, although Zika virus RNA has been found in breast milk (9).

Although the exact incubation period of Zika virus disease has yet to be determined, evidence from case reports and experience from related flavivirus infections indicate that the incubation period likely is 3 days to 2 weeks (12). Symptomatic disease is generally mild and characterized by two or more of the following: acute onset of fever, rash, arthralgia, or nonpurulent conjunctivitis $(2,13)$. The rash associated with Zika virus disease has been described as pruritic (13) and maculopapular (14).

The spectrum of Zika virus disease in neonates infected in the perinatal period is unknown. Perinatal transmission of Zika virus infection to infants from mothers infected near the time of delivery has been reported in two cases; one of these infants was asymptomatic, and the other had thrombocytopenia and a diffuse rash (9). Mother-to-infant transmission of dengue virus, a related flavivirus, during the perinatal period has resulted in findings in the newborn ranging from no symptoms to severe illness (including fever, thrombocytopenia, and hemorrhage), most often with fever onset during the first week of life (15). Similarly West Nile virus, another mosquito-borne flavivirus, has been transmitted during the perinatal period from three mothers to their infants, with each infant having one of the following manifestations: rash, viral encephalitis, and viral meningitis (16). The clinical features that might be observed in infants who acquire Zika virus during the perinatal period are currently unknown.

Available evidence regarding the spectrum of Zika virus disease in infants and children who are infected through mosquito bites indicates that most children are asymptomatic or have mild illness, similar to the findings seen in adults infected with Zika virus disease. In the outbreak in Yap Island, Micronesia, in 2007, among persons with clinical illness (age range $=1-76$ years), fever, macular or papular rash, arthralgia, and conjunctivitis were the most common signs and symptoms (2). In that outbreak, children aged 0-19 years had lower attack rates of confirmed 
and probable Zika virus disease than did adults aged $20-59$ years (2). Additional published data are available for 10 children, aged 3-16 years (17-22) with Zika virus disease in Africa, Asia, South America, and the Pacific. All 10 children had fever, but none had rash, two had conjunctivitis, and three had arthralgia. Vomiting was reported in two children $(17,22)$, and diarrhea was reported in two children (22). Among eight recent travel-related cases among children in the United States, all had rash and at least one other sign or symptom (fever, arthralgia, nonpurulent conjunctivitis) (CDC, unpublished data, 2016).

Deaths from Zika virus infection appear to be rare in persons of all ages. One death was reported in a female aged 15 years with sickle cell disease (hemoglobin SC), who experienced 4 days of fever, myalgia, abdominal pain and jaundice (18). A blood sample collected 5 days after illness onset was positive by reverse transcription-polymerase chain reaction (RT-PCR) for Zika virus RNA and negative for dengue, chikungunya, and yellow fever viruses (18). This patient died from complications of sickle cell disease after developing severe acute respiratory distress syndrome, hemothorax, and splenic sequestration (18). An additional death was reported in a female aged 16 years whose symptoms included headache, nausea, and petechiae; blood samples obtained 7 days after illness onset were positive by RT-PCR for Zika virus RNA (23). No further information was reported (23).

Guillain-Barré syndrome has been reported following Zika virus infection, although a causal link has not been established. Overall Guillain-Barré syndrome incidence appears to increase with increasing age (24). However, it is unclear how often Guillian-Barré syndrome after Zika virus infection has occurred in children (10). In French Polynesia, among 38 reported cases of Guillian-Barré syndrome after Zika virus infection, none occurred among children (25). One report from Brazil refers to six patients, aged 2-57 years, with neurologic syndromes (four with Guillain-Barré and two with acute disseminated encephalomyelitis) after laboratory-confirmed Zika virus infection; however, no further data were reported (13).

\section{Updated Recommendations for the Evaluation and Testing of Infants with Possible Congenital Zika Virus Infection}

Congenital infections result from intrauterine transmission from mother to fetus during pregnancy. Testing of infants with possible congenital Zika virus infection who were born to mothers who traveled to or resided in areas affected by Zika virus during pregnancy should be guided by 1 ) whether the infant had microcephaly or intracranial calcifications detected prenatally or at birth and 2) the mother's Zika virus testing results. The results of previous prenatal ultrasounds and maternal Zika virus testing should be reviewed, and a thorough newborn physical examination, with assessment of head (occipitofrontal) circumference, length, and weight, should be performed $(26,27)$. The evaluation of infants with microcephaly or intracranial calcifications or infants whose mothers have positive or inconclusive test results for Zika virus infection remains the same as described in the recommendations released on January 26 (Figure) (Box 1,2,3) (1). Infants without microcephaly or intracranial calcifications whose mothers have negative Zika virus test results or who were not tested for Zika virus should receive routine care (Figure). Because information on the effects of congenital Zika virus infection is limited, health care providers should exercise clinical judgment in the assessment of newborns with abnormalities other than microcephaly or intracranial calcifications who were born to mothers who traveled to or resided in an area with active Zika virus transmission during pregnancy. For these infants, health care providers should consider testing the mother before testing the infant. These guidelines will be updated as additional information becomes available.

\section{Guidelines for Evaluation and Management of Infants and Children Aged $<18$ Years with Possible} Acute Zika Virus Disease

Acute Zika virus disease should be suspected in an infant or child aged $<18$ years who 1 ) traveled to or resided in an affected area within the past 2 weeks and 2) has two or more of the following manifestations: fever, rash, conjunctivitis, or arthralgia. Acute Zika virus disease should also be suspected in an infant in the first 2 weeks of life 1) whose mother traveled to or resided in an affected area within 2 weeks of delivery and 2) who has two or more of the following manifestations: fever, rash, conjunctivitis, or arthralgia. Arthralgia can be difficult to detect in infants and young children and can manifest as irritability, walking with a limp (for ambulatory children), difficulty moving or refusing to move an extremity, pain on palpation, or pain with active or passive movement of the affected joint. Infants and older children can acquire Zika virus through mosquito-borne transmission. Infants can also be infected perinatally if the mother became infected with Zika virus during travel to or residence in an area with Zika virus transmission within 2 weeks of delivery. Infants whose mothers reported illness consistent with Zika virus disease near the time of delivery should be monitored for signs and symptoms of Zika virus disease. If an infant shows signs and symptoms of acute Zika virus disease within the first 2 weeks of life, both the mother and infant should be tested for Zika virus infection. Persons might be exposed to Zika virus infection through sexual contact with a person who has traveled to or resided in an area affected by Zika virus (11). 
FIGURE. Interim guidelines for the evaluation and testing of infants whose mothers traveled to or resided in an area with ongoing Zika virus transmission* during pregnancy ${ }^{\dagger, \S, \uparrow}$

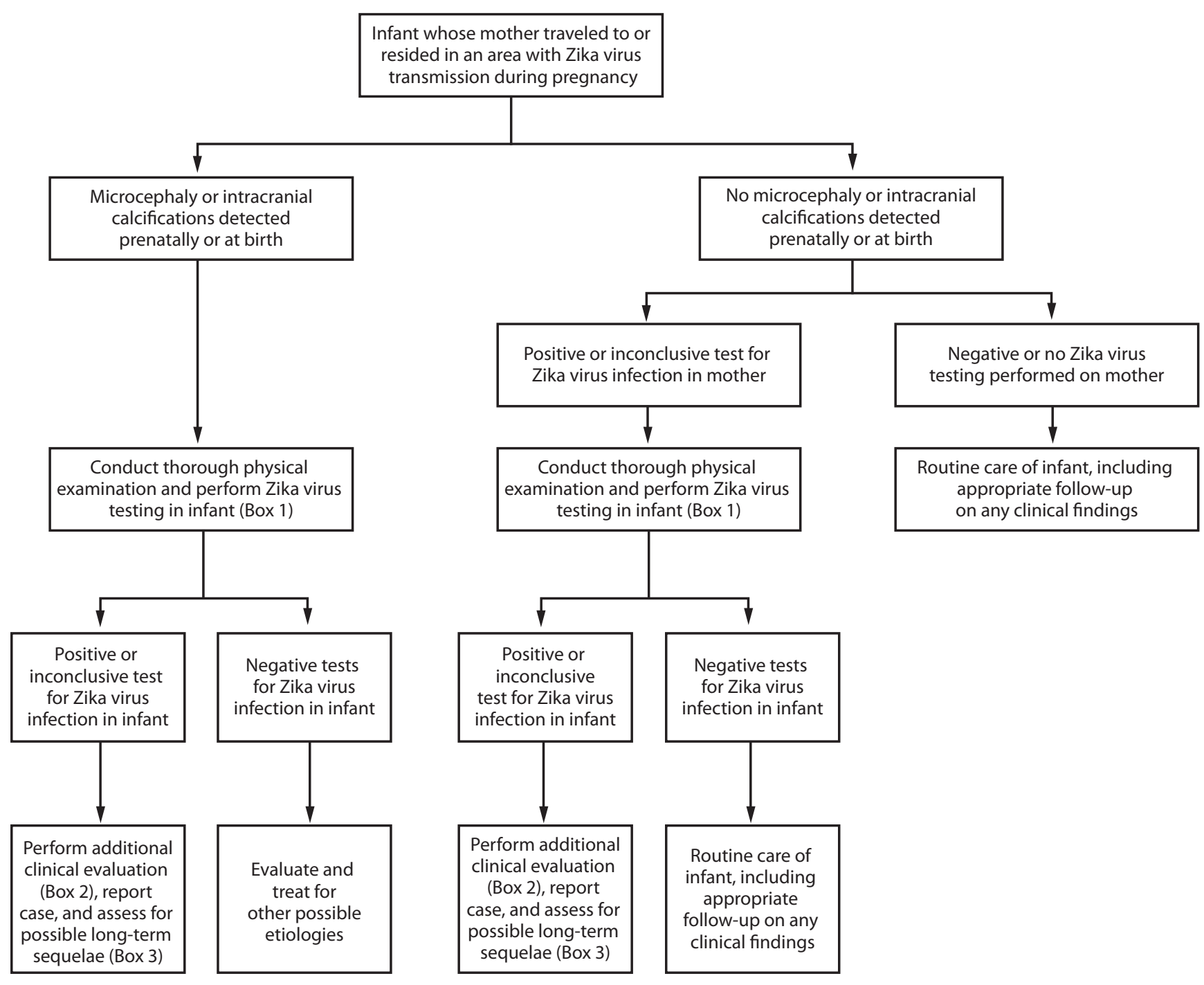

Adapted from: Staples, JE, Dziuban EJ, Fischer M, et al. Interim guidelines for the evaluation and testing of infants with possible congenital Zika virus infectionUnited States, 2016. MMWR Morb Mortal Wkly Rep 2016;65:63-7.

* Areas with Zika virus transmission are listed on the CDC website at http://wwwnc.cdc.gov/travel/page/zika-travel-information.

+ Microcephaly defined as occipitofrontal circumference less than the third percentile for gestational age and sex based on standard growth curves (26,27), not explained by other etiologies.

$\S$ Laboratory evidence of Zika virus infection includes 1) detectable Zika virus, Zika virus RNA, or Zika virus antigen in any clinical specimen; or 2) positive Zika virus $\operatorname{lgM}$ with confirmatory neutralizing antibody titers that are $\geq 4$-fold higher than dengue virus neutralizing antibody titers in serum or cerebrospinal fluid. Testing is considered inconclusive if Zika virus neutralizing antibody titers are $<4$-fold higher than denque virus neutralizing antibody titers.

" For infants, perform reverse transcription-polymerase chain reaction (RT-PCR) testing for Zika virus RNA and Zika virus and dengue virus IgM and neutralizing antibodies on serum collected from the umbilical cord or directly from infant within 2 days of birth, if possible. If cerebrospinal fluid is obtained for other reasons, test for Zika virus RNA, Zika virus IgM and neutralizing antibodies, and dengue virus IgM and neutralizing antibodies. Consider histopathologic evaluation of the placenta and umbilical cord with Zika virus immunohistochemical staining on fixed tissue and Zika virus RT-PCR on fixed and frozen tissue. More information on laboratory testing for Zika virus infection is available at http://www.cdc.gov/zika/state-labs/index.html.

Evaluation of infants and children for acute (symptom onset within the past 7 days) Zika virus infection should include testing of serum and, if obtained for other reasons, cerebrospinal fluid (CSF) specimens for evidence of Zika virus RNA using RT-PCR. If Zika virus RNA is not detected and symptoms have been present for $\geq 4$ days, serum may be tested for Zika virus immunoglobulin $\mathrm{M}(\mathrm{IgM})$ and neutralizing antibodies, and dengue virus IgM and neutralizing antibodies (Box 1). Laboratory evidence of Zika virus infection in an infant or child would include, in any clinical specimen, detectable Zika virus in culture, 
Zika virus RNA or antigen, or a clinical specimen positive for Zika virus IgM with confirmatory neutralizing antibody titers $\geq 4$-fold higher than dengue virus neutralizing antibody titers (1). If Zika virus antibody titers are $<4$-fold higher than dengue virus neutralizing antibody titers, test results for Zika virus are

BOX 1. Recommended Zika virus laboratory testing for infants and children when indicated ${ }^{*}, t, \S$

\section{For possible congenital Zika virus infection}

- Test infant serum for Zika virus RNA, Zika virus immunoglobulin $\mathrm{M}(\mathrm{IgM})$ and neutralizing antibodies, and dengue virus IgM and neutralizing antibodies. The initial sample should be collected either from the umbilical cord or directly from the infant within 2 days of birth, if possible.

- If cerebrospinal fluid is obtained for other studies, test for Zika virus RNA, Zika virus IgM and neutralizing antibodies, and dengue virus IgM and neutralizing antibodies.

- Consider histopathologic evaluation of the placenta and umbilical cord with Zika virus immunohistochemical staining on fixed tissue and Zika virus reverse transcription-polymerase chain reaction (RT-PCR) on fixed and frozen tissue.

- If not already performed during pregnancy, test mother's serum for Zika virus IgM and neutralizing antibodies, and dengue virus IgM and neutralizing antibodies.

\section{For possible acute Zika virus disease}

- If symptoms have been present for $<7$ days, test serum (and, if obtained for other reasons, cerebrospinal fluid) for Zika virus RNA by RT-PCR

- If Zika virus RNA is not detected and symptoms have been present for $\geq 4$ days, test serum (and, if obtained for other reasons, cerebrospinal fluid) for Zika virus IgM and neutralizing antibodies, and dengue virus IgM and neutralizing antibodies

Adapted from: Staples, JE, Dziuban EJ, Fischer M, et al. Interim guidelines for the evaluation and testing of infants with possible congenital Zika virus infectionUnited States, 2016. MMWR Morb Mortal Wkly Rep 2016;65:63-7.

* Indications for testing for congenital infection include 1) an infant with microcephaly or intracranial calcifications born to a woman who traveled to or resided in an area with Zika virus transmission while she was pregnant, or 2) an infant born to a mother with a positive or inconclusive test result for Zika virus infection.

${ }^{\dagger}$ Indications for testing during acute disease include: Infants and children aged $<18$ years who 1) traveled to or resided in an affected area within the past 2 weeks and 2) have $\geq 2$ of the following manifestations: fever, rash, conjunctivitis, or arthralgia. Infants in the first 2 weeks of life 1) whose mothers have traveled to or resided in an affected area within 2 weeks of delivery and 2) have $\geq 2$ of the following manifestations: fever, rash, conjunctivitis, or arthralgia.

${ }^{\S}$ More information on laboratory testing for Zika virus infection is available at http://www.cdc.gov/zika/state-labs/index.html.
BOX 2. Recommended clinical evaluation and laboratory testing for infants with possible congenital Zika virus infection

For all infants with possible congenital Zika virus infection, perform the following:

- Comprehensive physical examination, including careful measurement of occipitofrontal circumference, length, weight, and assessment of gestational age.

- Evaluation for neurologic abnormalities, dysmorphic features, splenomegaly, hepatomegaly, and rash or other skin lesions. Full body photographs and photographic documentation of any rash, skin lesions, or dysmorphic features should be performed. If an abnormality is noted, consultation with an appropriate specialist is recommended.

- Cranial ultrasound, unless prenatal ultrasound results from third trimester demonstrated no abnormalities of the brain.

- Evaluation of hearing by evoked otoacoustic emissions testing or auditory brainstem response testing, either before discharge from the hospital or within 1 month after birth. Infants with abnormal initial hearing screens should be referred to an audiologist for further evaluation.

- Ophthalmologic evaluation, including examination of the retina, either before discharge from the hospital or within 1 month after birth. Infants with abnormal initial eye evaluation should be referred to a pediatric ophthalmologist for further evaluation.

- Other evaluations specific to the infant's clinical presentation.

\section{For infants with microcephaly or intracranial} calcifications, additional evaluation includes the following:

- Consultation with a clinical geneticist or dysmorphologist.

- Consultation with a pediatric neurologist to determine appropriate brain imaging and additional evaluation (e.g., ultrasound, computerized tomography scan, magnetic resonance imaging, and electroencephalogram).

- Testing for other congenital infections such as syphilis, toxoplasmosis, rubella, cytomegalovirus infection, lymphocytic choriomeningitis virus infection, and herpes simplex virus infections. Consider consulting a pediatric infectious disease specialist.

- Complete blood count with platelet count and liver function and enzyme tests, including alanine aminotransferase, aspartate aminotransferase, and bilirubin.

- Consideration of genetic and other teratogenic causes based on additional congenital anomalies that are identified through clinical examination and imaging studies.

Adapted from: Staples, JE, Dziuban EJ, Fischer M, et al. Interim guidelines for the evaluation and testing of infants with possible congenital Zika virus infectionUnited States, 2016. MMWR Morb Mortal Wkly Rep 2016;65:63-7. 
BOX 3. Recommended long-term follow-up for infants with possible congenital Zika virus infection

\section{For all infants with possible congenital Zika virus infection, recommended long-term follow-up:}

- Report case to state, territorial, or local health department and monitor for additional guidance as it is released.

- Consider conducting additional hearing screen at age 6 months. Refer any child with developmental delay for an audiologic evaluation. Ensure that appropriate follow-up of abnormal newborn hearing screening has occurred.

- Carefully evaluate occipitofrontal circumference and developmental characteristics and milestones throughout the first year of life, in consultation with appropriate medical specialists (e.g., pediatric neurology, developmental and behavioral pediatrics, physical and speech therapy).

Adapted from: Staples, JE, Dziuban EJ, Fischer M, et al. Interim guidelines for the evaluation and testing of infants with possible congenital Zika virus infectionUnited States, 2016. MMWR Morb Mortal Wkly Rep 2016;65:63-7.

considered inconclusive (1). More information on laboratory testing can be found at http://www.cdc.gov/zika/state-labs/ index.html. Health care providers should notify their local, state or territorial health department of suspected Zika cases to arrange testing and so that action can be taken to decrease the risk for local transmission in areas with Aedes species mosquitoes.

Illness associated with Zika virus is usually mild in children, and treatment of Zika virus infection involves supportive care. Nonsteroidal anti-inflammatory drugs (NSAIDs) should be avoided until dengue virus is ruled out as the cause of illness, because of the potential for hemorrhagic complications of dengue fever, and should be avoided in all children aged $<6$ months $(28,29)$. Aspirin should not be used in children with acute viral illnesses because of its association with Reye's syndrome (30). The decision to obtain additional laboratory tests, diagnostic studies, and infectious disease consultation should be based on clinical judgment as guided by findings from a complete history and physical examination. Information on long-term outcomes among infants and children with acute Zika virus disease is limited (10); until more evidence is available to inform recommendations, routine pediatric care is advised for these infants and children.

\section{Guidelines for Breastfeeding for Mothers with Zika Virus Infection}

Zika virus RNA has been identified in breast milk, but attempts to culture the virus have been unsuccessful (9). No cases of Zika virus infection associated with breastfeeding have been reported. CDC encourages mothers with Zika virus infection and living in areas with ongoing Zika virus transmission to breastfeed their infants. Current evidence suggests that the benefits of breastfeeding outweigh the theoretical risks of Zika virus transmission through breast milk.

\section{Prevention of Zika Virus Infection in Infants and Children}

Prevention of mosquito bites is the primary means of preventing Zika virus infection in persosns of all ages traveling to or residing in areas with local Zika virus transmission. Mosquito bite prevention includes using air conditioning or window and door screens when indoors, wearing long-sleeved shirts and long pants, using permethrin-treated clothing and gear, and using insect repellents. When used as directed on the product label, most Environmental Protection Agency-registered insect repellents can be used to protect children aged $\geq 2$ months against mosquito bites. Oil of lemon eucalyptus should not be used in children aged $<3$ years (http://wwwnc.cdc.gov/travel/ yellowbook/2016/the-pre-travel-consultation/protectionagainst-mosquitoes-ticks-other-arthropods). Mosquito netting can be used to cover infants in carriers, strollers, or cribs to protect them from mosquito bites. Information on the safe use of insect repellents in children is available at http://www.epa.gov/ insect-repellents/using-insect-repellents-safely-and-effectively.

Persons with Zika virus infection should take steps to prevent mosquito bites for at least the first week of illness to decrease the risk for human-to-mosquito-to-human transmission. Health care providers should educate parents and caregivers about mosquito bite prevention in infants and children if they are traveling to or residing in areas affected by Zika virus; mosquitoes also carry other viruses in addition to Zika. More information about prevention of Zika virus infection can be found at http://www.cdc.gov/zika/prevention/index.html.

\section{Acknowledgment}

American Academy of Pediatrics.

\footnotetext{
${ }^{1}$ Division of Healthcare Quality Promotion, National Center for Emerging and Zoonotic Infectious Diseases, CDC; ${ }^{2}$ Epidemic Intelligence Service, CDC; ${ }^{3}$ Division of Nutrition, Physical Activity, and Obesity, National Center for Chronic Disease and Health Promotion, CDC; ${ }^{4}$ Division of Vector-Borne Diseases, National Center for Emerging and Zoonotic Infectious Diseases, CDC; 5 Division of Environmental Hazards and Health Effects, National Center for Environment Health, CDC; ${ }^{6}$ Division of Preparedness and Emerging Infections, National Center for Emerging and Zoonotic Infectious Diseases, CDC; ${ }^{7}$ Division of Congenital and Developmental Disorders, National Center on Birth Defects and Developmental Disabilities, CDC; ${ }^{8}$ Division of Parasitic Diseases and Malaria, Center for Global Health, CDC; ${ }^{9}$ Division of Reproductive Health, National Center for Chronic Disease Prevention and Health Promotion, CDC; ${ }^{10}$ Division of Public Health Information Dissemination, Center for Surveillance, Epidemiology, and Laboratory Services, CDC

Corresponding Author: Katherine E. Fleming-Dutra, eocbirthdef@cdc.gov.
} 


\section{References}

1. Staples JE, Dziuban EJ, Fischer M, et al. Interim guidelines for the evaluation and testing of infants with possible congenital Zika virus infection-United States, 2016. MMWR Morb Mortal Wkly Rep 2016;65:63-7. http://dx.doi. org/10.15585/mmwr.mm6503e3

2. Duffy MR, Chen TH, Hancock WT, et al. Zika virus outbreak on Yap Island, Federated States of Micronesia. N Engl J Med 2009;360:253643. http://dx.doi.org/10.1056/NEJMoa0805715

3. Ioos S, Mallet HP, Leparc Goffart I, Gauthier V, Cardoso T, Herida M. Current Zika virus epidemiology and recent epidemics. Med Mal Infect 2014;44:302-7. http://dx.doi.org/10.1016/j.medmal.2014.04.008

4. Hennessey M, Fischer M, Staples JE. Zika Virus Spreads to New Areas Region of the Americas, May 2015-January 2016. MMWR Morb Mortal Wkly Rep 2016;65:55-8. http://dx.doi.org/10.15585/mmwr.mm6503e1

5. Schuler-Faccini L, Ribeiro EM, Feitosa IM, et al.; Brazilian Medical Genetics Society-Zika Embryopathy Task Force. Possible association between Zika virus infection and microcephaly_Brazil, 2015. MMWR Morb Mortal Wkly Rep 2016;65:59-62. http://dx.doi.org/10.15585/ mmwr.mm6503e2

6. Martines RB, Bhatnagar J, Keating MK, et al. Notes from the field: Evidence of Zika virus infection in brain and placental tissues from two congenitally infected newborns and two fetal losses-Brazil. MMWR Morb Mortal Wkly Rep 2016;65:159-60. http://dx.doi.org/10.15585/ mmwr.mm6506e1

7. Mlakar J, Korva M, Tul N, et al. Zika virus associated with microcephaly. N Engl J Med 2016; Epub ahead of print. http://dx.doi.org/10.1056/ NEJMoa1600651

8. The Subcommittee on Arbovirus Laboratory Safety of the American Committee on Arthropod-Borne Viruses. Laboratory safety for arboviruses and certain other viruses of vertebrates. Am J Trop Med Hyg 1980;29:1359-81.

9. Besnard M, Lastere S, Teissier A, Cao-Lormeau V, Musso D. Evidence of perinatal transmission of Zika virus, French Polynesia, December 2013 and February 2014. Euro Surveill 2014;19:20751. http://dx.doi. org/10.2807/1560-7917.ES2014.19.13.20751

10. European Centre for Disease Prevention and Control. Rapid risk assessment: Zika virus epidemic in the Americas: potential association with microcephaly and Guillain-Barre syndrome. Stockholm, Sweden: European Centre for Disease Prevention and Control; 2015.

11. Oster AM, Brooks JT, Stryker JE, et al. Interim guidelines for prevention of sexual transmission of Zika virus-United States, 2016. MMWR Morb Mortal Wkly Rep 2016;65:120-1. http://dx.doi.org/10.15585/ mmwr.mm6505e1

12. Rudolph KE, Lessler J, Moloney RM, Kmush B, Cummings DA. Incubation periods of mosquito-borne viral infections: a systematic review. Am J Trop Med Hyg 2014;90:882-91. http://dx.doi.org/10.4269/ajtmh.13-0403

13. Minstério de Saúde. Protocolo de vigilância e resposta à ocorrência de microcefalia relacionada à infecção pelo vírus Zika 2015. http:// portalsaude.saude.gov.br/images/pdf/2015/dezembro/09/Microcefalia--Protocolo-de-vigil--ncia-e-resposta---vers--o-1----09dez2015-8h.pdf
14. Kwong JC, Druce JD, Leder K. Zika virus infection acquired during brief travel to Indonesia. Am J Trop Med Hyg 2013;89:516-7. http:// dx.doi.org/10.4269/ajtmh.13-0029

15. Pouliot SH, Xiong X, Harville E, et al. Maternal dengue and pregnancy outcomes: a systematic review. Obstet Gynecol Surv 2010;65:107-18.

16. O'Leary DR, Kuhn S, Kniss KL, et al. Birth outcomes following West Nile Virus infection of pregnant women in the United States: 2003-2004. Pediatrics 2006;117:e537-45. http://dx.doi.org/10.1542/peds.2005-2024

17. Alera MT, Hermann L, Tac-An IA, et al. Zika virus infection, Philippines, 2012. Emerg Infect Dis 2015;21:722-4. http://dx.doi.org/10.3201/eid2104.141707

18. Arzuza-Ortega L, Pérez-Tatis G, López-García H, et al. Fatal Zika virus infection in girl with sickle cell disease, Colombia[Letter]. Emerg Infect Dis 2016. Epub ahead of print. http://dx.doi.org/10.3201/eid2205.151934

19. Dupont-Rouzeyrol M, O'Connor O, Calvez E, et al. Co-infection with Zika and dengue viruses in 2 patients, New Caledonia, 2014. Emerg Infect Dis 2015;21:381-2. http://dx.doi.org/10.3201/eid2102.141553

20. Heang V, Yasuda CY, Sovann L, et al. Zika virus infection, Cambodia, 2010. Emerg Infect Dis 2012;18:349-51. http://dx.doi.org/10.3201/eid1802.111224

21. MacNamara FN. Zika virus: a report on three cases of human infection during an epidemic of jaundice in Nigeria. Trans R Soc Trop Med Hyg 1954;48:139-45. http://dx.doi.org/10.1016/0035-9203(54)90006-1

22. Olson JG, Ksiazek TG, Suhandiman, Triwibowo. Zika virus, a cause of fever in Central Java, Indonesia. Trans R Soc Trop Med Hyg 1981;75:389-93. http://dx.doi.org/10.1016/0035-9203(81)90100-0

23. Centro de operaçós de emergênecias em saúde pública sobre microcefalias. Informe epidemiológico no 02/2015-Semana epidemiológica 47 (22 a 28/11/2015): Monitoramento dos casos de microcefalias no Brasil. http://portalsaude.saude.gov.br/images/pdf/2015/novembro/30/COESMicrocefalias---Informe-Epidemiol--gico---SE-47---30nov2015.pdf

24. Sejvar JJ, Baughman AL, Wise M, Morgan OW. Population incidence of Guillain-Barré syndrome: a systematic review and meta-analysis. Neuroepidemiology 2011;36:123-33. http://dx.doi.org/10.1159/000324710

25. European Centre for Disease Prevention and Control. Rapid risk assessment: Zika virus infection outbreak, French Polynesia. Stockholm, Sweden: European Centre for Disease Prevention and Control; 2014.

26. World Health Organization. The WHO child growth standards. Geneva, Switzerland: World Health Organization. http://www.who.int/ childgrowth/standards/en/

27. University of Calgary. Welcome to the Fenton Preterm Growth Chart: 2013 Growth Chart. http://ucalgary.ca/fenton/2013chart

28. Sullivan JE, Farrar HC; Section on Clinical Pharmacology and Therapeutics; Committee on Drugs. Fever and antipyretic use in children. Pediatrics 2011;127:580-7. http://dx.doi.org/10.1542/peds.2010-3852

29. Tomashek KM, Sharp TM, Margolis HS. Dengue. Chapter 3. In: Brunette GW, ed. CDC Health information for international travel 2016.

30. Hurwitz ES, Barrett MJ, Bregman D, et al. Public Health Service study of Reye's syndrome and medications. Report of the main study. JAMA 1987;257:1905-11. http://dx.doi.org/10.1001/jama.1987.03390140075030 